\title{
The Role of Checklists and Human Factors for Improved Patient Safety in Plastic Surgery
}

\author{
Claude Oppikofer, M.D., \\ B.Law \\ David Schwappach, Prof. \\ Dr., M.P.H. \\ Montreux, Zürich, and Bern, \\ Switzerland
}

Learning Objectives: After studying the article, participants should be able to: 1. Describe the role of human factors and nontechnical skills for patient safety and recognize the need for customization of surgical checklists. 2. Apply encouragement to speaking up and understand the importance of patient involvement for patient safety. 3. Recognize the potential for improvement regarding patient safety in their own environment and take a leading role in the patient safety process. 4 . Assess their own safety status and develop measures to avoid unnecessary distraction in the operating room.

Summary: Over the past 20 years, there has been increased attention to improving all aspects of patient safety and, in particular, the important role of checklists and human factors. This article gives a condensed overview of selected aspects of patient safety and aims to raise the awareness of the reader and encourage further study of referenced literature, with the goal of increased knowledge and use of proven safety methods. The CME questions should help indicate where there is still potential for improvement in patient safety, namely, in the field of nontechnical skills. (Plast. Reconstr. Surg. 140: 812e, 2017.) o he important role of human factors in patient safety has been studied extensively over the past 20 years. From this focus, many useful tools, such as surgical checklists and techniques of crew resource management, have been introduced into surgical practice. There is scientific evidence that these tools contribute greatly to patient safety, if used properly. The purpose of this article is to give a condensed overview of selected aspects of patient safety and to provide a better understanding of the significant role of human factors in improving patient safety. The reader is encouraged to use proven patient safety methods while considering the human factors. The extensive reference list provides additional resources for further reading on this critical subject.

\section{PREVENTABLE ADVERSE EFFECTS}

Following the publication of To Err Is Human: Building a Safer Health System by the Institute of Medicine in the year 2000, awareness for the need to prevent human error grew among the medical community. ${ }^{1}$ It also became evident that human

From Chirurgie Plastique Riviera; the Swiss Patient Safety Foundation; and the Institute of Social and Preventive Medicine, University of Bern.

Received for publication February 18, 2017; accepted June 19, 2017.

Copyright (C) 2017 by the American Society of Plastic Surgeons

DOI: $10.1097 /$ PRS.0000000000003892 errors were the main cause of preventable adverse events in surgery. "Preventable adverse effects" refers to harm from medical care rather than an underlying disease that occurred caused by error or failure to apply an accepted strategy for prevention. ${ }^{2}$ Acknowledging that "Systems that rely on error-free performance are doomed to fail," a lack of appropriate measures for the sake of patient safety was established. ${ }^{3}$ Although much effort has always been made to train surgeons and operating room staff in their knowledge and technical skills, the aspects of nontechnical skills—namely, teamwork, leadership, situational awareness, decision-making, task management, and communication-have long been neglected..$^{4-6}$

\section{CHIECIKLISTS}

Surgical checklists have been increasingly used since 2009, especially after the publication of the first global survey on the use of a surgical checklist by Haynes et al. made it clear that this tool, adopted from the aviation industry, would have an increasing impact on patient safety. ${ }^{7}$ Much of the present literature proves that the introduction of checklists has had a positive impact on safety ${ }^{8,9}$ (Reference 8 Level of Evidence: Therapeutic, I).

Disclosure: The authors have no financial interest to declare in relation to the content of this article. 
However, there have also been critical reports on their effect. ${ }^{10-12}$ Careful analysis of these reports shows that the lack of positive impact was because of the expectation of immediate measurable results after the introduction of the safety checklist, when in reality, the process represents a gradual, step-by-step improvement plan. Furthermore, success can be achieved only if the leadership pays close attention to the quality of the checklists and the performance of the teams that use them. Furthermore, it is well documented that "safety checklists are beneficial for operating room teamwork and communication and this may be one mechanism through which patient outcomes are improved." 13

It is important to note that the World Health Organization, when it introduced its surgical checklist in 2009, indicated that "This checklist is not intended to be comprehensive. Additions and modifications to fit local practice are encouraged." 14 In addition, the implementation manual for checklists emphasizes the necessity of modifying the checklist to promote a culture of safety. ${ }^{15}$ This indicates that the World Health Organization checklist should be used only as an example or guideline and that a checklist has to be adapted to the specific needs of its users. Or, as Harden says, "While powerful, checklists are not 'one size fits all' and must be customized to local practices, which is especially true in a plastic surgeon's office."16 Furthermore, different surgical specialties, such as plastic surgery, will have different needs, and a checklist will only be well accepted by the surgeons and staff if it is designed by a plastic surgery team. ${ }^{17}$ Although the support of hospital leadership is essential for the success of any safety measure, a top-down enforcement will create only a false feeling of safety. Acceptance of a checklist comes from participation of the users in the design.

The World Health Organization checklist is essentially a perioperative checklist. Efforts to expand the checklist concept to a "practice checklist" covering the patient's course from initial consultation all the way through postoperative care have been proven to contribute to better safety. ${ }^{18,19}$

With the introduction of surgical checklists, especially after 2009 , much importance has been given to filling out a specific form with checkmarks and signatures. This may be useful to monitor the compliance of the users, but documentation and administrative control must not be the purpose of a checklist, as this is contrary to all safety-relevant efforts. Aviation has proven that reading though a checklist without a pen is just as useful. Attempts to run checklists without check-marking items on a paper with a pen should be encouraged, provided that they fit the needs and culture of a team. ${ }^{20}$

Implementation of a checklist without team training is not useful. ${ }^{21,22}$ Of course, the concept of a team is completely different in health care, as compared to the military or athletics, for example. For office-based surgery and small surgery centers where a surgeon is in control of staff and their training, it is possible to achieve a concept of true teams. In many other settings, such as large hospitals, it has been noted that, in surgery, teams are actually "teams in name only," because "union work rules, financial constraints, and restriction of flexibility have discouraged most hospital administrations from creating and implementing true teams." 23 Teams are put together for each operation. They consist of professional individuals who often barely know each other and who sometimes work together for the first time. ${ }^{24}$ They have not been trained together. This makes team behavior challenging. Nevertheless, it should be considered an imperative of surgical leadership to address these difficulties and find innovative solutions that fit into the operating room workplace and its culture. ${ }^{25}$ The training for the use of checklists thus contributes to leading surgical ad hoc teams to optimal performance and responsibility of all individuals. Surgeons' leadership is reflected by the fact that as far as surgical safety checklist performance is concerned, it is better when surgeons lead the checklist process and when all team members are present and paused..$^{26}$

Checklist completion has proven to be an essential factor for outcomes. Although mortality was not significantly reduced, Mayer et al. reported that "complications could be prevented if full completion of the checklist was implemented"27 (Level of Evidence: Therapeutic, II).

\section{Addressing Human Factors with Crew Resource Management}

Airlines introduced crew resource management, the concept of maximizing effectiveness and safety by optimal use of all available resources of a team, especially the human factor, approximately 40 years ago as an important safety measure. ${ }^{28}$ Although the work of a cockpit crew differs in many ways from that of a surgical team, many mental processes used for ensuring safety of the operations are common: communication, situational awareness, stress management, interpersonal interactions, and teamwork. These processes can be improved by crew resource management, which typically addresses nontechnical skills. 
Crew resource management programs require time and money, but they have proven to offer a high return on investment. ${ }^{29} \mathrm{~A}$ "crew resource management crash course" will not produce longterm effects, and it is not enough to think that blindly copying a tool from aviation will improve safety, as we may have tended to believe. The Agency for Healthcare Research and Quality, an agency within the U.S. Department of Health \& Human Services, concluded in a recent report that we wrongly were hoping to find solutions to medical errors by simply adopting some techniques drawn from aviation and other "safe industries." On the contrary, "making patients safe will require ongoing efforts to improve practices, training, information technology, and culture. It will need top-down resources and leadership, accompanied by bottom-up wisdom and innovation. It will depend on a strong policy environment that creates appropriate incentives, while avoiding an environment in which providers' enthusiasm and creativity are sapped by an overly rigid, prescriptive bureaucracy and set of rules." ${ }^{30}$ In summary, it has to be accepted that safety concepts cannot be borrowed and adopted on a 1:1 scale from aviation, but need to be developed by health care specialists for their specific use.

\section{Speaking Up and Stopping the Line}

Speaking up and encouragement to do so can be considered to be an essential element of crew resource management. ${ }^{31}$ There are numerous clinical examples to illustrate how speaking up can prevent adverse events. ${ }^{32}$ However, there are many reasons why nurses, for example, may not speak up to a surgeon if they notice a problem (i.e., fear of being ridiculed for perhaps being incorrect, or the fear of being blamed by a superior for interfering). In contrast, analysis of problems, major complications, or casualties shows that in a majority of the cases, someone along the line saw an issue arise and did not mention it. Encouragement of speaking up and creating a climate allowing all members of a team to speak up without the risk of being punished is therefore a true act of medical leadership. Patient care is the foremost concern of the operating room staff, and the surgeon should be aware of each team member's contribution to the positive outcome of an operation.

Stopping the line is a technique used in the automobile industry in which all employees on the assembly line have the power and responsibility to stop a process whenever they notice a defect or safety issue on the assembly line. ${ }^{33}$ In health care, and especially in surgery, all team members must be empowered to stop the line if they sense or discover an essential safety breach. ${ }^{34}$

Structured language can make it easier to speak up and be assertive when it is needed. Using a "script" of set phrases that the team has agreed on in advance can make interactions more predictable and less "personal." 35 Although a stopthe-line expression must be clearly understood as such by all members of a team, it is useful that it does not sound too alarming. A typical script to stop the line is, "I need clarity."

\section{Patient Involvement}

Patients are, of course, the ones most motivated to care about their safety. This has been demonstrated by their support for the delivery of safety improvements. ${ }^{36}$ Therefore, we must not neglect to include patients in our safety protocols. Especially in plastic surgery, where many operations are performed under local anesthesia, it makes sense to involve patients in checklists and encourage them to speak up. This will not break down the doctor-patient relationship, but on the contrary will emphasize the partnership. ${ }^{37}$

\section{Self-Assessment of Safety Status}

All health care professionals should consider their own assessment of their ability to perform correctly a personal responsibility. Such an assessment should be performed before surgery by every member of the team, including the surgeon. This is also the occasion for speaking up about safety-relevant issues. In "Team Strategies \& Tools to Enhance Performance \& Patients Safety" (Team STEPPS), the Agency for Healthcare Research and Quality gives an example of how such an assessment can be conducted ${ }^{34}$ It must be emphasized that this assessment is a private matter. Obligation to document or report it will be counterproductive. However, in some situations, a team member may be comfortable communicating personal matters to other members of the team (e.g., fatigue).

\section{Fatigue}

Fatigue as a safety issue is well recognized and dealt with in aviation. ${ }^{38}$ In medicine, it is often neglected and most probably underreported, possibly because of a culture where surgeons feel weak if they admit fatigue. Fatigue must not necessarily prevent someone from working in a surgical team, but it may be something to communicate to other team members. A culture where someone 
is allowed (but not forced) to say "I slept only 3 hours last night because my baby was sick" will create better team performance.

\section{Human Factors in Long Operations}

Plastic surgery often implies long operation times, and human factors have a particular significance. It has been shown that the risk of retained surgical items (a never event!) is higher in longer operations ${ }^{39}$ In plastic surgery, where long operations are common, it has been demonstrated that surgery duration is an independent predictor of complications, with a significantly increased risk above 3 hours $^{40}$ (Level of Evidence: Therapeutic, III). Long operations have several other impacts that can influence patient safety because of human factors. ${ }^{41}$ These include a greater number of handovers, pointing to the usefulness of structuring handovers. ${ }^{42}$ Fatigue becomes increasingly relevant with prolonged operations and must be dealt with. Planning micropauses during such operations may be a way to prevent fatigue and associated loss of accuracy ${ }^{43}$ (Level of Evidence: Therapeutic, II). Basic human needs such as eating, drinking, and eliminating become increasingly important with longer operating times and may influence patient safety. ${ }^{44}$

\section{Preoperative Marking and Safety}

It is uncontested that preoperative marking helps to avoid operations of the wrong patient or the wrong side. However, it has other positive effects for patient safety, namely, the fact that it lets the patient participate in the safety measures about his or her surgery and shows the efforts being made. Thus, it is a perfect occasion for patient involvement. A standardized way of marking will help to avoid misunderstandings. Masud et al. recommended the use of an arrow to mark the correct side. ${ }^{45}$ This will avoid wrong interpretations. Indeed, an arrow leaves no doubt about which side has to be operated on, whereas a cross could be interpreted as a "no" (Figs. 1 and 2).

The positive impact of preoperative marking should not draw attention away from other safety considerations, namely, hygiene. Rooney et al. tested the use of the same marking pen for a series of patients and found no risk for sterility. ${ }^{46}$ However, the discussion about the safety of this method is controversial, and other authors do report potential problems. ${ }^{47,48}$ Water-based pens especially carry a potential danger of crossinfection. ${ }^{49}$ Furthermore, marking pens make microlesions to the skin, which could become

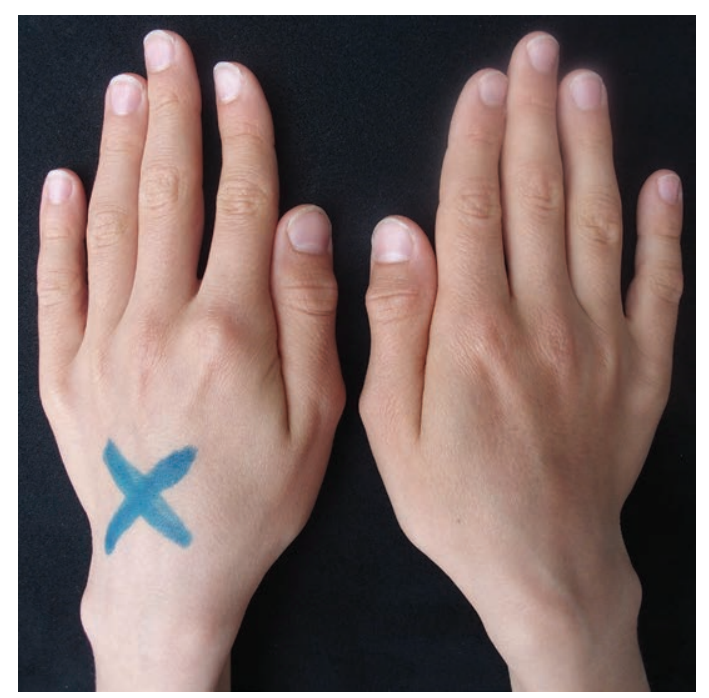

Fig. 1. This way of marking the hand to be operated could be interpreted as "Stop, do not operate on the left hand!"

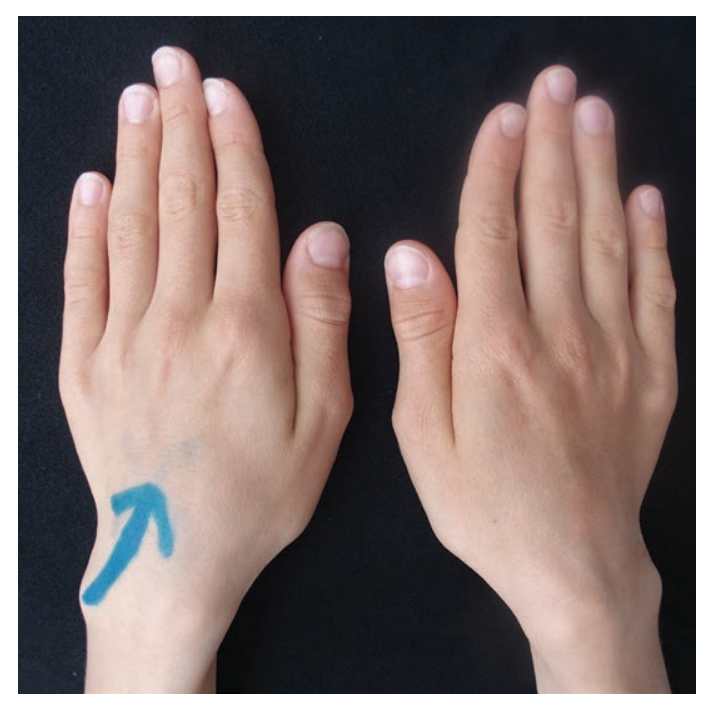

Fig. 2. An arrow leaves no doubt which hand has to be operated on.

contaminated with hospital germs. Therefore, our recommendation for surgical marking is to use the same criteria as for hand hygiene..$^{50}$ Single-use marking pens should thus be recommended for surgical marking.

\section{Smartphone Use and Other Distractions}

Originally, the risks described for patient safety with regard to cell phones have been those of unperceived contamination close to the patient. ${ }^{51}$ With the increased use of personal smartphones, a new dimension of human factors has entered the operating room. Although there is no evidence so far to show that regulating smartphone use in the operating room improves patient safety, it seems 
to be common sense that the distraction caused by their use, especially if used for texting or writing e-mails, keeps staff from fulfilling other tasks, such as observation of the operation. . $^{2-54}$

Other human-caused distractions have an influence on patient safety, too. An observational study by Wheelock et al. showed that the most prevalent distractions for surgeons were those initiated by external staff, followed by case-irrelevant conversations. Case-irrelevant conversations were associated with poorer team performance. Irrelevant conversations initiated by surgeons were associated with lower teamwork in surgeons. In contrast, Weigl et al. found that case-irrelevant communications may be beneficial for reducing mental fatigue and stress in routine cases, whereas procedural interruptions may contribute to deterioration of surgeons' mental focus..$^{55,56}$

\section{CONGILUSIONS}

This review of specific topics of patient safety shows there is much potential for improvement in this area. The significance of human factors and nontechnical skills for the safety of patients in all of health care, and especially in surgery, has been demonstrated by many studies. In addition, the introduction of surgical checklists in 2009 has contributed to an increasing consciousness for these and other safety improvement tools. However, further studies are necessary to assess long-term success. It is the hope of the authors that the selected topics covered in this article, along with the CME questions and answers, will help the reader find possible gaps in his or her own activity and encourage further reading about patient safety in the literature referenced here and elsewhere.

\section{Claude Oppikofer, M.D., B.Law Chirurgie Plastique Riviera Grand Rue 3 \\ Montreux 1820, Switzerland claude@oppikofer.com}

\section{ACIKNOWLED GMIENT}

The authors thank Theresa Feeser, M.B.A., for editorial assistance with this article.

\section{REFERENCES}

1. Institute of Medicine, Committee on Quality of Health Care in America. To Err Is Human: Building a Safer Health System. Washington, DC: National Academy Press; 2000.

2. Agency for Healthcare Research and Quality. Patient Safety Network (PSNet): Adverse events, near misses, and errors. Available at: https://psnet.ahrq.gov/primers/primer/34/ adverse-events-near-misses-and-errors. Accessed May 13, 2017.
3. Leape LL. Error in medicine. JAMA 1994;272:1851-1857.

4. Agha RA, Fowler AJ, Sevdalis N. The role of non-technical skills in surgery. Ann Med Surg (Lond.) 2015;4:422-427.

5. Yule S, Flin R, Paterson-Brown S, Maran N. Non-technical skills for surgeons in the operating room: A review of the literature. Surgery 2006;139:140-149.

6. Flin R, Yule S, Paterson-Brown S, Maran N, Rowley D, Youngson G. Teaching surgeons about non-technical skills. Surgeon 2007;5:86-89.

7. Haynes AB, Weiser TG, Berry WR, et al.; Safe Surgery Saves Lives Study Group. A surgical safety checklist to reduce morbidity and mortality in a global population. $N$ Engl J Med. 2009;360:491-499.

8. Haugen AS, Søfteland E, Almeland SK, et al. Effect of the World Health Organization checklist on patient outcomes: A stepped wedge cluster randomized controlled trial. Ann Surg. 2015;261:821-828.

9. Haynes AB, Berry WR, Gawande AA. What do we know about the safe surgery checklist now? Ann Surg. 2015;261:829-830.

10. Urbach DR, Govindarajan A, Saskin R, Wilton AS, Baxter NN. Introduction of surgical safety checklists in Ontario, Canada. N Engl J Med. 2014;370:1029-1038.

11. Reames BN, Scally CP, Thumma JR, Dimick JB. Evaluation of the effectiveness of a surgical checklist in Medicare patients. Med Care 2015;53:87-94.

12. Leape LL. The checklist conundrum. $N$ Engl $J$ Med. 2014;370:1063-1064.

13. Russ S, Rout S, Sevdalis N, Moorthy K, Darzi A, Vincent C. Do safety checklists improve teamwork and communication in the operating room? A systematic review. Ann Surg. 2013;258:856-871.

14. World Health Organization. WHO surgical safety checklist. Available at: http://www.who.int/patientsafety/safesurgery/ checklist/en/. Accessed May 12, 2017.

15. World Health Organization. Implementation manual: WHO surgical safety checklist 2009. Available at: http://apps.who. int/iris/bitstream/10665/44186/1/9789241598590_eng. pdf. Accessed May 12, 2017.

16. Harden SW. Six things every plastic surgeon needs to know about teamwork training and checklists. Aesthet Surg J. 2013;33:443-448.

17. Oppikofer C. Checklists in Plastic Surgery: A Powerful Safety Tool (If Used Correctly!) Plastic Surgery Pulse News, 2012. Available at: http://safetyculture.ch/page2/files/QMPChecklist.pdf. Accessed October 5, 2017.

18. Rosenfield L. Beyond the checklist: Achieving practice excellence. Plast Reconstr Surg. 2012;130:969-970.

19. Anger J, Letizio N, Orel M, de Souza Junior JL, dos Santos MM. A preoperative checklist in esthetic plastic surgery. Rev Bras Cir Plast. 2011;26:525-529.

20. Ong AP, Devcich DA, Hannam J, Lee T, Merry AF, Mitchell SJ. A 'paperless' wall-mounted surgical safety checklist with migrated leadership can improve compliance and team engagement. BMJ Qual Saf. 2016;25:971-976.

21. Kobler I, Mascherek A, Bezzola P. How patient safety programmes can be successfully implemented: An example from Switzerland (in German). Z Evid Fortbild Qual Gesundhwes. 2015;109:132-137.

22. Borchard A, Schwappach DL, Barbir A, Bezzola P. A systematic review of the effectiveness, compliance, and critical factors for implementation of safety checklists in surgery. Ann Surg. 2012;256:925-933.

23. Buchman SR. Are the new changes in our operating rooms really making us safer and better surgeons? Plast Reconstr Surg. 2013;131:1205-1206.

\section{6e}


24. Mazzocco K, Petitti DB, Fong KT, et al. Surgical team behaviors and patient outcomes. Am J Surg. 2009;197:678-685.

25. Oppikofer C. Are the new changes in our operating rooms really making us safer and better surgeons? Plast Reconstr Surg. 2014;133:600e-602e.

26. Russ S, Rout S, Caris J, et al. Measuring variation in use of the WHO surgical safety checklist in the operating room: A multicenter prospective cross-sectional study. J Am Coll Surg. 2015;220:1-11.e4.

27. Mayer EK, Sevdalis N, Rout S, et al. Surgical Checklist Implementation Project: The impact of variable WHO checklist compliance on risk-adjusted clinical outcomes after national implementation: A longitudinal study. Ann Surg. 2016;263:58-63.

28. Oppikofer C. Crew Resource Management in Plastic Surgery: Lessons From Aviation Plastic Surgery Pulse News, 2009. Available at: http://safetyculture.ch/page2/files/CRMQMP.pdf. Accessed October 5, 2017.

29. Moffatt-Bruce SD, Hefner JL, Mekhjian H, et al. What is the return on investment for implementation of a crew resource management program at an academic medical center? Am J Med Qual. 2017;32:5-11.

30. U.S. Department of Health \& Human Services, Agency for Healthcare Research and Quality. Making patients safer II. Available at: http://www.ahrq.gov/sites/default/files/wysiwyg/research/findings/evidence-based-reports/services/ quality/ptsafetyII-full.pdf. Accessed December 11, 2016.

31. Reid J. Speaking up: A professional imperative. J Perioper Pract. 2013;23:114-118.

32. Oppikofer C. Commentary on: Six things every plastic surgeon needs to know about teamwork training and checklists. Aesthet Surg J. 2013;33:449-451.

33. Yasuhiro M. Toyota Production System: An Integrated Approach to Just-In-Time. 4th ed. Boca Raton, Fla: CRC Press; 2012.

34. Agency for Healthcare Research and Quality. Pocket Guide: TeamSTEPPS. Team strategies and tolls to enhance performance and patient safety. Available at: http://www. ahrq.gov/teamstepps/instructor/essentials/pocketguide. html\#twochall. Accessed December 3, 2016.

35. Agency for Healthcare Research and Quality. AHRQ TeamSTEPPS Training. Available at: http://www.ahrq.gov/ sites/default/files/wysiwyg/professionals/education/curriculum-tools/teamstepps/lep/traintrainers/lepigtrainer. pptx. Accessed December 12, 2016.

36. Russ SJ, Rout S, Caris J, et al. The WHO surgical safety checklist: Survey of patients' views. BMJ Qual Saf. 2014;23:939-946.

37. Schwappach DL. Review: Engaging patients as vigilant partners in safety. A systematic review. Med Care Res Rev. 2010;67:119-148.

38. International Air Transport Association. Fatigue Risk Implementation Systems: Implementation Guide for Operators. Montreal, Quebec, Canada: International Air Transport Association; 2011.

39. Moffatt-Bruce SD, Cook CH, Steinberg SM, Stawicki SP. Risk factors for retained surgical items: A meta-analysis and proposed risk stratification system. J Surg Res. 2014;190:429-436.

40. Hardy KL, Davis KE, Constantine RS, et al. The impact of operative time on complications after plastic surgery: A multivariate regression analysis of 1753 cases. Aesthet Surg J. 2014;34:614-622.

41. Oppikofer C. Safety and Human Factors in Long Duration Surgery Plastic Surgery Pulse News, 2016. Available at: http://safetyculture.ch/page2/files/Print\%20Article.pdf. Accessed October 5, 2017.

42. Catchpole KR, de Leval MR, McEwan A, et al. Patient handover from surgery to intensive care: Using Formula 1 pit-stop and aviation models to improve safety and quality. Paediatr Anaesth. 2007;17:470-478.

43. Dorion D, Darveau S. Do micropauses prevent surgeon's fatigue and loss of accuracy associated with prolonged surgery? An experimental prospective study. Ann Surg. 2013;257:256-259.

44. Lewis MS, Snyder PJ, Pietrzak RH, Darby D, Feldman RA, Maruff $P$. The effect of acute increase in urge to void on cognitive function in healthy adults. Neurourol Urodyn. 2011;30:183-187.

45. Masud D, Moore A, Massouh F. Current practice on preoperative correct site surgical marking. J Perioper Pract. 2010;20:210-214.

46. Rooney J, Khoo OK, Higgs AR, Small TJ, Bell S. Surgical site marking does not affect sterility. ANZJ Surg. 2008;78:688-689.

47. Tadiparthi S, Shokrollahi K, Juma A, Croall J. Using marker pens on patients: A potential source of cross infection with MRSA. Ann R Coll Surg Engl. 2007;89:661-664.

48. Cronen G, Ringus V, Sigle G, Ryu J. Sterility of surgical site marking. J Bone Joint Surg Am. 2005;87:2193-2195.

49. Ballal MS, Shah N, Ballal M, O’Donoghue M, Pegg DJ. The risk of cross-infection when marking surgical patients prior to surgery: Review of two types of marking pens. Ann R Coll Surg Engl. 2007;89:226-228.

50. Tanner J, Dumville JC, Norman G, Fortnam M. Surgical hand antisepsis to reduce surgical site infection. Cochrane Database Syst Rev. 2016;1:CD004288.

51. Jeske HC, Tiefenthaler W, Hohlrieder M, Hinterberger G, Benzer A. Bacterial contamination of anaesthetists' hands by personal mobile phone and fixed phone use in the operating theatre. Anaesthesia 2007;62:904-906.

52. Pınar HU, Karaca O, Doğan R, Konuk ÜM. Smartphone use habits of anesthesia providers during anesthetized patient care: A survey from Turkey. BMC Anesthesiol. 2016;16:88.

53. Attri JP, Khetarpal R, Chatrath V, Kaur J. Concerns about usage of smartphones in operating room and critical care scenario. SaudiJ Anaesth. 2016;10:87-94.

54. Jorm CM, O'Sullivan G. Laptops and smartphones in the operating theatre: How does our knowledge of vigilance, multi-tasking and anaesthetist performance help us in our approach to this new distraction? Anaesth Intensive Care 2012;40:71-78.

55. Wheelock A, Suliman A, Wharton R, et al. The impact of operating room distractions on stress, workload, and teamwork. Ann Surg. 2015;261:1079-1084.

56. Weigl M, Antoniadis S, Chiapponi C, Bruns C, Sevdalis $\mathrm{N}$. The impact of intra-operative interruptions on surgeons' perceived workload: An observational study in elective general and orthopedic surgery. Surg Endosc. 2015;29:145-153. 